\title{
High-altitude treatment in atopic and nonatopic patients with severe asthma
}

\author{
Lucia H. Rijssenbeek-Nouwens*, Karin B. Fieten*, Adriaan O. Bron*, \\ Simone Hashimoto\#, Elisabeth H. Bel ${ }^{\#}$ and Els J. Weersink ${ }^{\#}$
}

ABSTRACT: The beneficial effects of high-altitude treatment in asthma have been attributed to allergen avoidance. Recent evidence shows that this treatment also improves airway inflammation in nonallergic patients. We hypothesised that high-altitude treatment is clinically equally effective in patients with severe refractory asthma, with or without allergic sensitisation.

In a prospective observational cohort study, 137 adults with severe refractory asthma (92 with allergic sensitisation), referred for high-altitude $(1,600 \mathrm{~m})$ treatment in Davos, Switzerland, were consecutively included. We measured asthma control (Asthma Control Questionnaire (ACQ)), asthma-related quality of life (Asthma-Related Quality of Life Questionnaire (AQLQ)), sino-nasal symptoms (Sino-Nasal Outcome Test (SNOT-20)), medication requirement, postbronchodilator (post-BD) forced expiratory volume in $1 \mathrm{~s}$ (FEV1), 6-min walking distance (6MWD), total immunoglobulin $(\mathrm{Ig}) \mathrm{E}$, blood eosinophils and exhaled nitric oxide fraction ( $\mathrm{FeNO}$ ) at admission and after 12 weeks.

Sensitised and nonsensitised patients showed similar improvements in ACQ (-1.4 and -1.5 , respectively; $p=0.79)$, AQLQ (1.6 and 1.5 , respectively; $p=0.94)$, SNOT-20 $(-0.7$ and -0.5 , respectively; $p=0.18)$, post-BD $\mathrm{FEV}_{1}(6.1 \%$ and $5.8 \%$ pred, respectively; $p=0.87)$, 6MWD (+125 $\mathrm{m}$ and $+147 \mathrm{~m}$, respectively; $p=0.43)$ and oral steroids ( $40 \%$ versus $44 \%$, respectively; $\mathrm{p}=\mathbf{0 . 5 1}$ ). Sensitised patients showed a larger decrease in total IgE, blood eosinophils and $F$ eNO.

High-altitude treatment improves clinical and functional parameters, and decreases oral corticosteroid requirement in patients with severe refractory asthma, irrespective of allergic sensitisation.

KEYWORDS: Air pollution, corticosteroids, house dust mite

$\mathbf{T}$ he majority of patients with mild-tomoderate asthma can be treated adequately with inhaled corticosteroids combined with long-acting bronchodilators [1]. However, this therapy is not sufficient to reach asthma control in patients with severe refractory asthma [2]. For these patients, there are only a few effective therapeutic options available, including systemic corticosteroids, which have serious adverse effects [3], and monoclonal antibodies against immunoglobulin (Ig)E, which are indicated only for patients with allergic asthma [4]. For nonatopic patients with severe asthma, however, there is an urgent need for better therapies [5].

High-altitude treatment has been applied for decades in patients with asthma, especially in children and adolescents with moderate-tosevere atopic disease [6-9]. The success of this treatment has long been attributed to the absence of house dust mite allergens at altitudes $>1,600 \mathrm{~m}$ [10]. However, two recent studies, one in children and one in adults, have shown that high-altitude treatment also reduces airway inflammation in patients with allergies other than house dust mite, or no allergies at all [11, 12]. This suggests that factors other than allergen avoidance contribute to the beneficial influence of high-altitude treatment, and that this treatment might be a valuable therapeutic option for patients with severe, nonatopic asthma.

The present prospective observational study was designed to test the hypothesis that high-altitude treatment is equally effective in severe asthmatic patients with or without house dust mite allergy and with or without any allergies. To that end, we compared the effects of 12 weeks of high-altitude treatment on clinical, physiological and inflammatory parameters in patients with severe refractory
AFFILIATIONS

*Dutch Asthma Centre Davos, Davos, Switzerland.

"Dept of Respiratory Medicine, Academic Medical Centre, University of Amsterdam, Amsterdam, The Netherlands.

\section{CORRESPONDENCE}

L.H. Rijssenbeek-Nouwens Dutch Asthma Centre Davos Herman Burchartstrasse 1 7260 Davos

Switzerland E-mail: rrijssenbeek@nad.ch

Received:

Nov 092011

Accepted after revision:

Feb 192012

First published online:

March 222012 
asthma with and without sensitisation to house dust mite or other aeroallergens, who were referred to the Dutch Asthma Centre Davos (Davos, Switzerland) for high-altitude treatment.

\section{PATIENTS AND METHODS \\ Patients}

Between January 2008 and January 2010, all adult patients who were referred to the Dutch Asthma Centre Davos with a diagnosis of severe, refractory asthma according to American Thoracic Society (ATS) criteria [13] were asked to participate in the study. They all used high doses of inhaled corticosteroids $(\geqslant 1,260 \mu \mathrm{g}$ per day of beclomethasone or equivalent) or oral corticosteroids combined with long-acting bronchodilators for $\geqslant 1$ yr. All patients were symptomatic and had had at least one severe exacerbation during the past year requiring a course of oral corticosteroids, or were receiving chronic oral corticosteroid therapy. All patients were either nonsmokers or exsmokers. In order to exclude patients with smoking-related chronic obstructive pulmonary disease, patients with a smoking history $>15$ yrs had to show a reversibility in forced expiratory volume in $1 \mathrm{~s}(\mathrm{FEV} 1)$ to short-acting $\beta$-agonist of $>12 \%$ predicted. Before being referred for the high-altitude clinic inhalation technique, adherence to treatment and optimal avoidance of exposure to allergens and cigarette smoke was checked using a questionnaire completed by the referring pulmonologist. The study was approved by the Ethics Committee of the Academic Medical Centre of the University of Amsterdam (Amsterdam, the Netherlands). All patients gave their written informed consent. This study was registered at the Netherlands Trial Register, under NTR 1277.

\section{Study design}

We conducted a 12-week prospective observational cohort study in patients with severe, refractory asthma who were referred to the Dutch Asthma Centre Davos for high-altitude treatment in order to optimise their disease. Patients were assessed and evaluated according to a systematic protocol at entry and after a 12-week multidisciplinary comprehensive treatment.

\section{High-altitude treatment: climate and specialised treatment}

The high-altitude climate offers an environment with low levels of allergic and nonallergic bronchoconstricting stimuli. The multidisciplinary treatment at high altitude consists of a personalised, structured and comprehensive treatment plan aimed at achieving full asthma control and improving patient's physical condition with the lowest possible dose of asthma medication. The quintessence of the treatment is the daily supervised exercise training indoors and outdoors in the trigger free environment.

\section{Questionnaires}

All patients filled in standard questionnaires including questions about current symptoms, medical history, age at asthma onset, smoking habits and medication usage. The dose of inhaled corticosteroids was expressed in equivalents of inhaled beclomethasone and the dose of oral corticosteroids in milligrammes of prednisolone equivalents.

The six-item Asthma Control Questionnaire (ACQ) was used to assess the level of asthma control [14]. Responses to each item are rated on a six-point scale. The mean of the six items in the ACQ between 0 (totally controlled) and 6 (severely uncontrolled) was used.

The Asthma Quality of Life Questionnaire, standardised version $(A Q L Q(S))$ [15] was used to measure asthma-related quality of life. The mean of the 32 items in the AQLQ between 1 (very poor quality of life) and 7 (best quality of life) was used.

The rhino-sinusitis health status was measured by the 20question Sino-Nasal Outcome Test (SNOT-20); the possible range of the SNOT-20 score is $0-5$, with a higher score indicating a greater rhinosinusitis-related health burden [16].

\section{Pulmonary function}

Pulmonary function was measured by spirometry. FEV1 was assessed before and after inhaled administration of $400 \mu \mathrm{g}$ salbutamol and expressed as the \% predicted value. \% pred values were obtained from the report of QUANJER et al. [17]. 6-min walk tests were performed according to ATS guidelines [18].

\section{Allergy tests}

Total IgE in peripheral blood was assessed by fluroenzyme immunoassay (UniCAP ${ }_{\mathbb{R}}$; Pharmacia \& Upjohn, Uppsala, Sweden) and expressed in $\mathrm{kU} \cdot \mathrm{L}^{-1}$. Sensitisation to specific IgE was assessed with a panel of common aero-allergens (house dust mite, mixed grass and birch pollen, cat and dog dander, and Aspergillus) by UniCAP ${ }_{\circledast}$ and expressed in $\mathrm{kU} \cdot \mathrm{L}^{-1}$. Patients were classified as sensitised to house dust mite if $\mathrm{IgE}$ to house dust mite was $>0.35 \mathrm{kU} \cdot \mathrm{L}^{-1}$.

\section{Markers of systemic and airway inflammation}

Eosinophils in peripheral blood were measured by standard automated cell counter.

Exhaled nitric oxide fraction ( $F$ eNO) was measured using a chemiluminescence analyser (Niox; Aerocrine AB, Solna, Sweden) [19].

\section{Statistical analysis}

Changes in clinical, functional and immunological parameters from admission to discharge were analysed by paired t-tests and Wilcoxon signed rank test for paired samples. Unpaired

\begin{tabular}{|c|c|c|c|}
\hline & $\begin{array}{l}\text { HDM-sensitised } \\
\text { patients }\end{array}$ & $\begin{array}{c}\text { Non-HDM- } \\
\text { sensitised patients }\end{array}$ & $p$-value \\
\hline Subjects $n$ & 68 & 69 & \\
\hline Female & $50(73)$ & $43(63)$ & 0.251 \\
\hline Age yrs & $41.5 \pm 14.5$ & $48 \pm 15.3$ & 0.009 \\
\hline $\begin{array}{l}\text { Sensitised for any } \\
\text { inhaled allergen }\end{array}$ & $68(100)$ & $24(35)$ & $<0.001$ \\
\hline Ex-smokers & $28(40)$ & $22(32)$ & 0.321 \\
\hline BMI kg· $\mathrm{m}^{-2}$ & $28.8 \pm 5.9$ & $28.1 \pm 6.9$ & 0.551 \\
\hline Age of asthma onset yrs & $4(0-45)$ & $12(1-63)$ & 0.001 \\
\hline Asthma duration yrs & $25(2-71)$ & $33(1-65)$ & 0.455 \\
\hline
\end{tabular}

Data are presented as $n(\%)$, mean \pm SD or median (range), unless otherwise stated. BMI: body mass index. 


\begin{tabular}{|c|c|c|c|}
\hline $\begin{array}{l}\text { Baseline } \\
\text { without a }\end{array}$ & $\begin{array}{l}\text { racteristics } \\
\text { allergic sen }\end{array}$ & $\begin{array}{l}\text { f patients with } \\
\text { tisation }\end{array}$ & and \\
\hline & $\begin{array}{l}\text { Sensitised } \\
\text { patients }\end{array}$ & $\begin{array}{l}\text { Nonsensitised } \\
\text { patients }\end{array}$ & $\mathrm{p}$-value \\
\hline Subjects n & 92 & 45 & \\
\hline Females & $50(73)$ & $35(78)$ & 0.08 \\
\hline Age yrs & $44 \pm 15.8$ & $48 \pm 14.2$ & 0.124 \\
\hline Sensitised to HDM & 68 (74) & 0 & $<0.001$ \\
\hline Ex-smokers & $32(35)$ & $18(40)$ & 0.555 \\
\hline$B M I \mathbf{~ k g} \cdot \mathrm{m}^{-2}$ & $28.0 \pm 56.7$ & $29.4 \pm 5.7$ & 0.261 \\
\hline Age of asthma onset yrs & $5(0-58)$ & $12(1-63)$ & 0.001 \\
\hline Asthma duration yrs & $33(1-71)$ & $24(3-66)$ & 0.455 \\
\hline
\end{tabular}

t-tests and Mann-Whitney were used to analyse the differences between groups. A p-value $<0.05$ was considered statistically significant. SPSS version 17.0 (SPSS Inc., Chicago, IL, USA) was used for the analysis.

\section{RESULTS}

Of 180 patients who were asked to participate in the study, four patients refused for personal reasons. 137 patients completed the 12 -week follow-up period and were included in the analysis. The other 39 patients left Davos at an earlier time-point. There were no differences in baseline characteristics between patients who did and did not participate in the study (data not shown). Patient characteristics at baseline are shown in table 1 for 68 house dust mite-sensitised and 69 non-house dust mite-sensitised patients. In table 2 the characteristics of 92 patients with any sensitisation to common aeroallergens and 45 without sensitisation are shown. Changes from baseline in clinical, physiological and inflammatory parameters in patients with and without sensitisation to house dust mite are shown in table 3, and with and without sensitisation to any aeroallergen in table 4 .

After 12 weeks of high-altitude treatment, improvements in asthma control, asthma-related quality of life, sino-nasal symptoms, FEV1, 6-min walking distance and total $\operatorname{IgE}$ were observed in patients with and without sensitisation to house dust mite, while the daily requirement for oral corticosteroids was decreased. $14(48 \%)$ out of 29 patients sensitised to house dust mite and 15 (36\%) out of 41 patients without house dust mite sensitisation could discontinue maintenance treatment with oral steroids completely. In the patients who could not discontinue oral corticosteroid treatment, the mean daily dose of prednisolone equivalent decreased from mean \pm SD $26.3 \pm 13.3$ to $14.3 \pm 10.3 \mathrm{mg}(\mathrm{p}=0.006)$ in those sensitised to house dust mite, and from $29.2 \pm 24.0$ to $14.4 \pm 8.8 \mathrm{mg}(\mathrm{p}=0.001)$ in the non-house dust mite-sensitised patients.

There was a decrease in peripheral blood eosinophils and exhaled nitric oxide in patients with house dust mite sensitisation, which was not observed in non-house dust mite-sensitised patients. The effects of high altitude did not differ between patients with or without sensitisation to house dust mite for all other parameters (table 3).

Similar results were obtained when comparing the effects of high-altitude treatment between patients with or without

TABLE 3 Values at baseline and after 12 weeks of high-altitude treatment in patients with and without house dust mite (HDM) sensitisation

\begin{tabular}{|c|c|c|c|c|c|c|c|}
\hline & \multicolumn{3}{|c|}{ HDM-sensitised patients } & \multicolumn{3}{|c|}{ Non-HDM-sensitised patients } & \multirow[t]{2}{*}{$\begin{array}{l}\text { Significance between } \\
\text { groups } p \text {-value }\end{array}$} \\
\hline & Baseline & 12 weeks & p-value & Baseline & 12 weeks & p-value & \\
\hline Subjects $n$ & & 68 & & & 69 & & \\
\hline ACQ score $\#$ & $3.0 \pm 1.0$ & $1.6 \pm 1.2$ & $<0.001$ & $3.3 \pm 1.0$ & $1.8 \pm 1.0$ & $<0.001$ & 0.965 \\
\hline AQLQ scoreף & $4.0 \pm 0.9$ & $5.6 \pm 1.0$ & $<0.001$ & $3.8 \pm 0.9$ & $5.3 \pm 1.1$ & $<0.001$ & 0.952 \\
\hline SNOT-20 score ${ }^{+}$ & $2.2 \pm 0.8$ & $1.5 \pm 1.1$ & $<0.001$ & $2.2 \pm 0.76$ & $1.6 \pm 1.0$ & $<0.001$ & 0.412 \\
\hline Patients on OCS & $29(43)$ & $15(22)$ & $<0.001$ & $41(59)$ & $26(38)$ & $<0.001$ & 0.87 \\
\hline OCS mg $\cdot$ day $^{-1}$ & $0(0-60)$ & $0(0-40)$ & $<0.001$ & $5.0(0-110)$ & $0(0-40)$ & $<0.001$ & 0.668 \\
\hline ICS $\mu \mathrm{g} \cdot \mathrm{day}^{-1}$ & $1600(200-8000)$ & $1600(0-8000)$ & 0.533 & $1600(0-8000)$ & $1600(0-8000)$ & 0.40 & 0.584 \\
\hline FEV $_{1} \%$ pred & $88.4 \pm 20.4$ & $94.2 \pm 20.1$ & 0.001 & $86.5 \pm 26.2$ & $92.8 \pm 23.1$ & 0.004 & 0.838 \\
\hline 6MWD m & $516 \pm 178$ & $636 \pm 219$ & $<0.001$ & $430 \pm 182$ & $575 \pm 197$ & $<0.001$ & 0.360 \\
\hline Total IgE kU· $\mathrm{L}^{-1}$ & $376(7-5000)$ & $245(6-4682)$ & 0.003 & $94(5-1781)$ & $58(5-1961)$ & 0.039 & 0.211 \\
\hline $\begin{array}{c}\text { Blood eosinophils } \\
\text { per } \mu \mathrm{L} \text { of blood }\end{array}$ & $235(0-1050)$ & $210(50-570)$ & 0.033 & $200(0-880)$ & $200(0-630)$ & 0.207 & 0.025 \\
\hline FeNO ppb & $27.6(5-209)$ & $18.4(3-70)$ & $<0.001$ & $16(5-224)$ & $16(1-61)$ & 0.058 & 0.033 \\
\hline
\end{tabular}


TABLE 4 Values at baseline and after 12 weeks of high-altitude treatment in patients with and without any allergic sensitisation

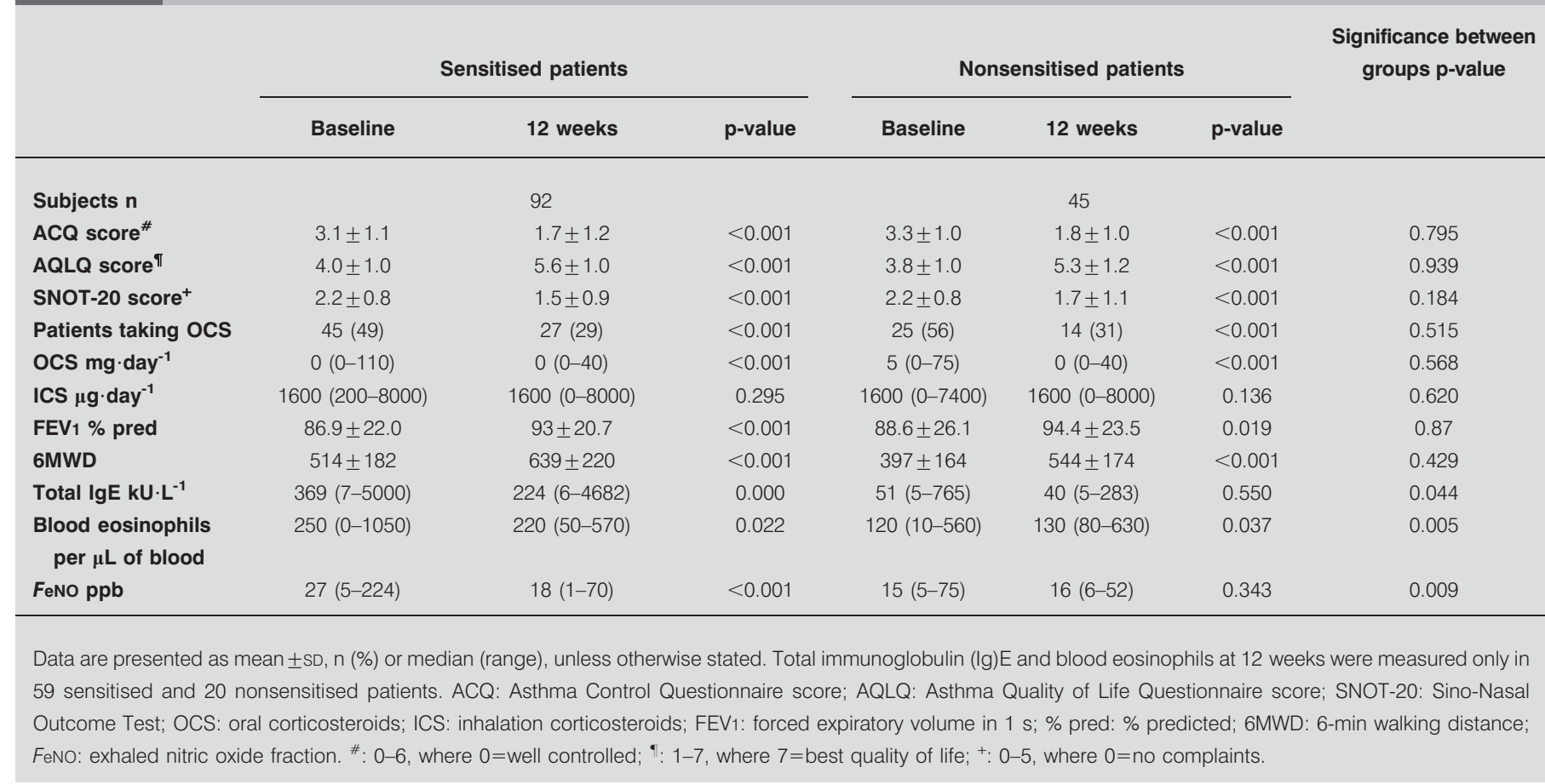
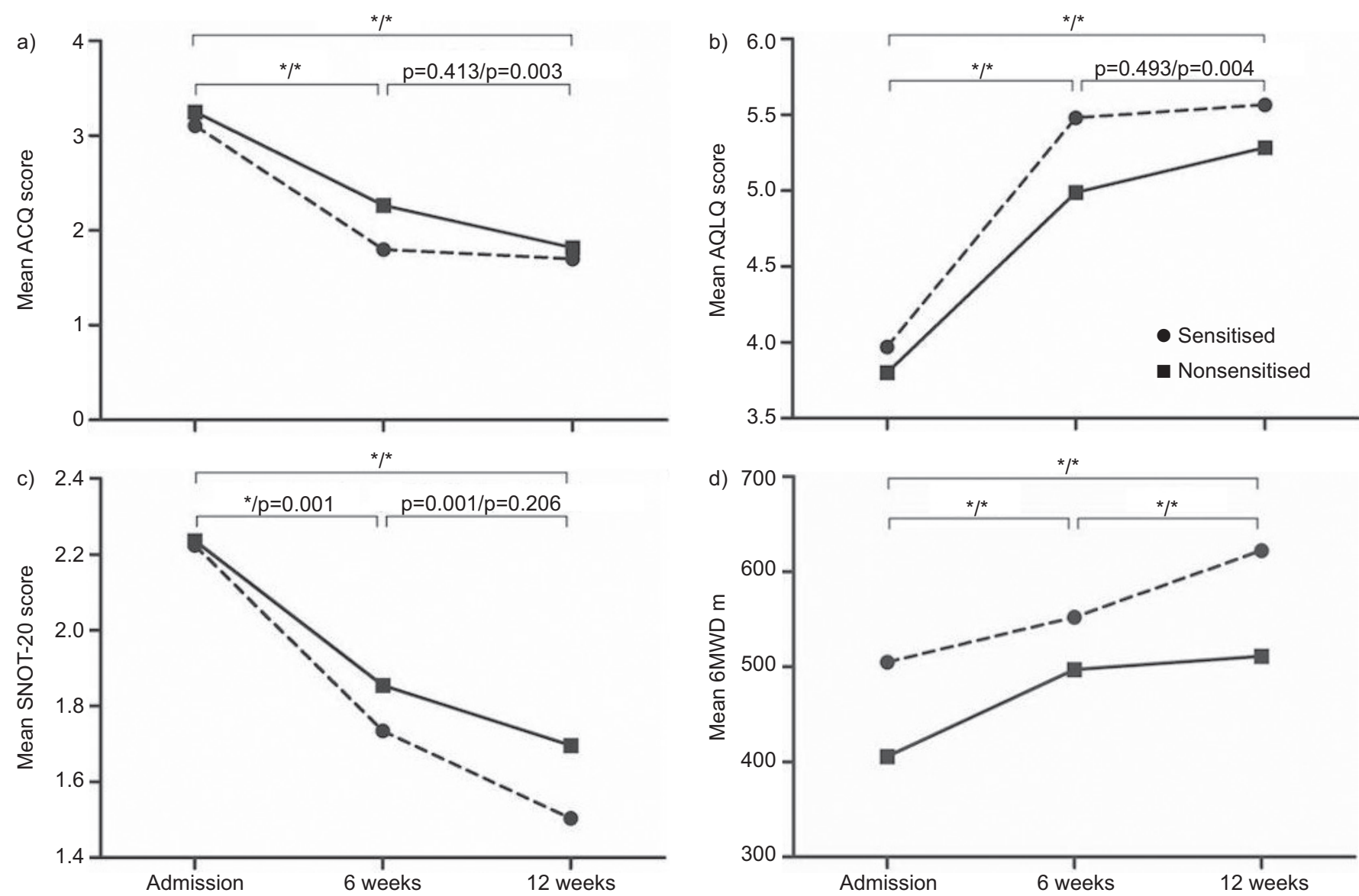

FIGURE 1. The mean a) Asthma Control Questionnaire (ACQ) score, b) Asthma-related Quality of Life Questionnaire (AQLQ) score, c) Sino-Nasal Outcome Test (SNOT20) score and d) 6-min walking distance (6MWD) on at admission, and after 6 and 12 weeks of high-altitude treatment in patients with and without sensitisation to any allergen. ${ }^{*}: \mathrm{p}<0.05 . * / *$ : $\mathrm{p}$-values for patientswith/without sensitisation to any allergen. 
sensitisation to any airborne allergens (table 4 and figs 1 and $2)$. Both allergic $(n=92)$ and nonallergic $(n=45)$ patients with severe asthma showed improvements in clinical and physiological parameters. However, improvements in total IgE levels, peripheral blood eosinophils and exhaled nitric oxide were observed only in patients with severe allergic asthma.

\section{DISCUSSION}

This study shows that patients with severe refractory asthma benefit from high-altitude treatment irrespective of sensitisation to house dust mite, or any common aero-allergen. The beneficial effect in clinical and functional parameters coincides with a decrease in oral corticosteroid requirement. Asthma symptoms, asthma-related quality of life, rhino-sinusitis symptoms, lung function and exercise performance improve to a similar extent in sensitised and nonsensitised patients, whereas total $\operatorname{IgE}$, peripheral blood eosinophils and exhaled nitric oxide decrease only in sensitised patients. These findings suggest that high-altitude treatment is a valuable treatment option not only for patients with house dust mite allergic asthma, but also for patients with severe, refractory, nonallergic or "intrinsic" asthma.

This is the first study showing improvements in clinical and physiological parameters of high-altitude treatment in adults with severe, refractory asthma who are not sensitised to house dust mite. A large number of studies have shown beneficial effects of high-altitude treatment on asthma control, asthma-related quality of life, airway hyperresponsiveness and markers of inflammation in children and adolescents with house dust mite allergic, moderate-to-severe asthma [6-9, 20,21]. Two studies have investigated the effects of high-altitude treatment on markers of airway inflammation and observed similar improvement in FeNO in allergic and nonallergic patients, but in these studies, the effects on upper and lower airway symptoms, lung function, exercise capacity or medication requirement were not systematically addressed [11, 12].

Our study is unique in that it systematically evaluated the effects of high-altitude treatment in a large cohort of welldescribed patients with severe refractory asthma, and showed that beneficial effects occur irrespective of sensitisation to airborne allergens.

In our study, the treatment programme was adjusted to the individual needs and capabilities of the patients. Theoretically, this might have introduced a treatment bias. However, the essence of the treatment, being the change in environmental exposure from a polluted, industrialised environment at sea level to the low-trigger environment at high altitude, was similar for both allergic and nonallergic patients. Moreover, there were no specific treatment adjustments related to the presence or absence of allergic sensitisation. Therefore, we do not believe that differences in treatments can explain the results of the present study.

It can also be argued that any individual, even without asthma, might benefit from a stay in the mountain climate. This might be true, but our patients had objective improvements in asthma symptoms, lung function and inflammatory parameters, as well as large improvements in exercise capacity and decreases in oral corticosteroid requirement, suggesting that high-altitude
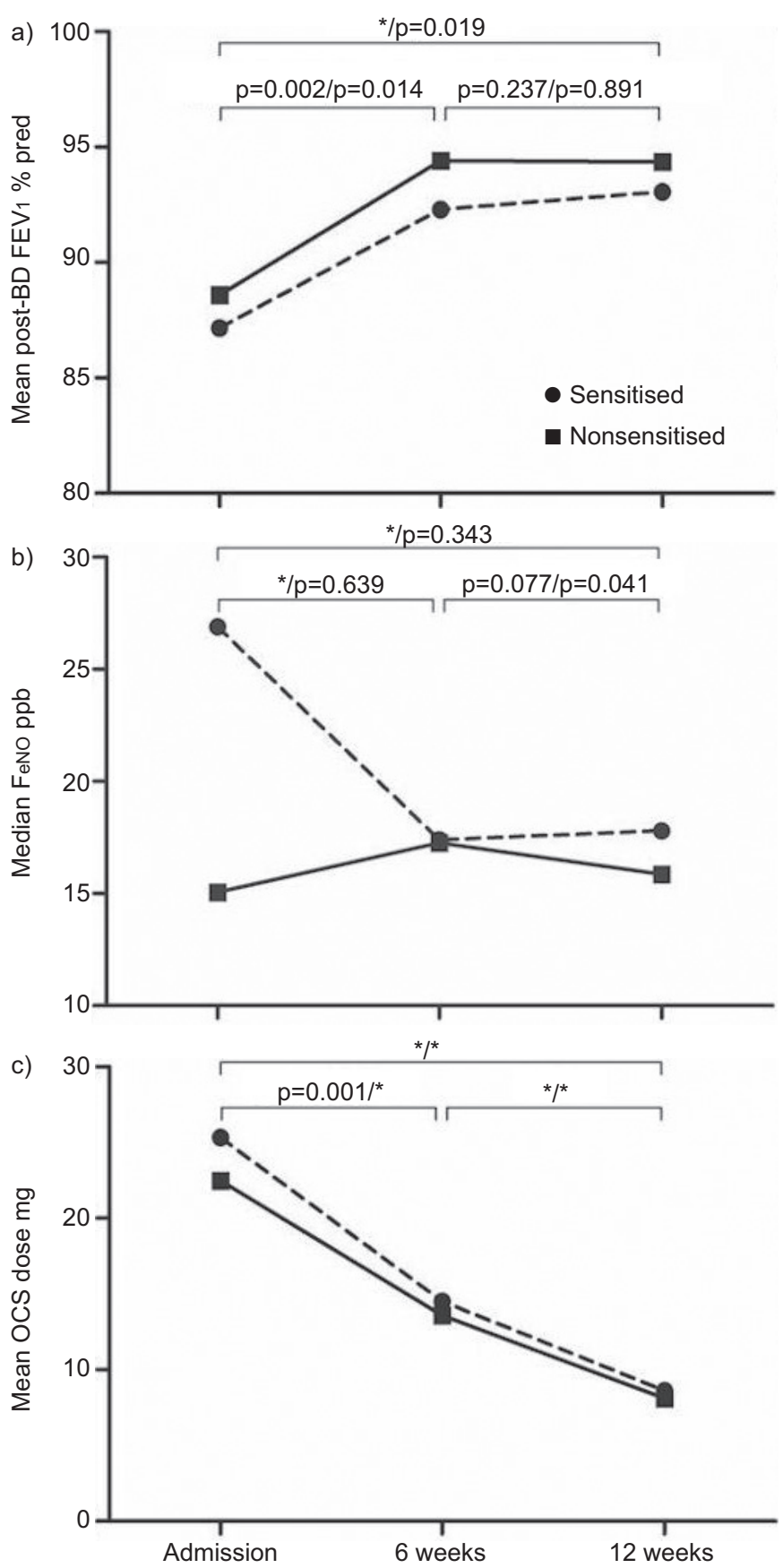

FIGURE 2. The mean a) forced expiratory volume in $1 \mathrm{~s}(\mathrm{FEV} 1), \mathrm{b})$ exhaled nitric oxide fraction ( $\mathrm{FeNO}$ ) and c) oral corticosteroid (OCS) dose at the start of the study, and after 6 and 12 weeks of high-altitude treatment in patients with and without sensitisation to any allergen. OCS dose was assessed only in patients on maintenance oral corticosteroid treatment at the start of the study. \% pred: $\%$ predicted; post-BD: postbronchodilator. *: $p<0.05 . *{ }^{*}$ : p-values for patients with/ without sensitisation to any allergen.

climate is particularly beneficial for patients with severe respiratory diseases. The improvements were the more striking since the patients in our study were referred to the high-altitude clinic because of long standing very severe, poorly controlled, refractory asthma by pulmonologists who are specialised in asthma care and working in academic hospitals or tertiary 
referral centres in the Netherlands. Clearly, decrease of exposure to allergens was not the only reason for the beneficial effect, given the similar improvement in sensitised and nonsensitised patients.

How can we explain the beneficial effects of high-altitude treatment in nonsensitised patients with severe asthma? Several factors might play a role [22]. First, the mountain outdoor climate in the Alps not only has very low levels of house dust mite, fungal spores and pollens [23], but is also far less polluted than the climate in other parts of Europe at sea level, such as the Netherlands [10, 24-26]. Secondly, the highaltitude climate may have a direct physiological benefit because of the lower viscosity of the air and lower oxygen pressure. The decreased density of the air reduces respiratory resistances and increases inspiratory and expiratory flows, promoting full expansion of the lungs and decreasing lung resistance, which makes it easier to breathe. This effect may be comparable with that of other low density gases, such as heliox, which have been applied successfully in patients with acute severe asthma [27]. Thirdly, by moving to the mountains, the patients are moved away from psychological stress at home or at work [28]. Psychological stress has been shown to enhance airway inflammation by modulating immune cell function through neural and hormonal pathways [29]. Finally, the Alps are well known for their abundance of sunshine. Exposure to ultraviolet light stimulates vitamin D photosynthesis in the skin and may modulate the immune system, thereby potentially reducing the severity of chronic diseases, such as asthma [30].

Because of all the above qualities, the low-trigger climate at high altitude provides the ideal environment for all patients with severe refractory asthma, whether sensitised or nonsensitised to house dust mites or common inhalation allergens.

The results of our study have clinical implications. As the clinical benefits of high-altitude treatment are similar in sensitised and nonsensitised patients, there is no reason to restrict this treatment to children and adolescents with atopic asthma and predominant house dust mite allergy [31]. Because of its beneficial effects on asthma control, exercise capacity and corticosteroid requirement, it should be offered to all patients with severe refractory asthma, including middle-aged and older adults with intrinsic disease [32]. The favourable climate at high altitude provides ideal circumstances to participate in pulmonary rehabilitation programmes and to improve exercise capacity and physical fitness for prolonged periods of time. Multidisciplinary, tailor-made treatment programmes, such as the one offered by the Dutch Asthma Centre Davos, are likely to lead to better outcomes than similar interventions at sea level, although this has to be confirmed by randomised controlled trials [33].

In conclusion, we have shown that high-altitude treatment is a valuable treatment option for patients with severe refractory asthma, both for patients who are sensitised and not sensitised to airborne allergens. It significantly improves symptoms of the upper and lower airways, asthma-related quality of life, lung function and exercise capacity with a simultaneous reduction in the requirement for oral corticosteroids or even discontinuation of these drugs. High-altitude treatment is one of the very few efficacious treatments for patients with severe refractory asthma, and has no adverse effects. It is probably the best therapeutic option for patients with severe nonatopic asthma, for whom there is no treatment available other than systemic corticosteroids to control their disease.

\section{SUPPORT STATEMENT}

We thank the Netherlands-Davos Society for their support.

\section{CLINICAL TRIAL}

This study is registered at the Netherlands Trial Register with identifier NTR 1277.

\section{STATEMENT OF INTEREST}

Statements of interest for L.H. Rijssenbeek-Nouwens, A.O. Bron and E.H. Bel can be found at www.erj.ersjournals.com $/ \mathrm{site} / \mathrm{misc} / \mathrm{state}-$ ments.xhtml

\section{REFERENCES}

1 Global Strategy for Asthma Management and Prevention, Global Initiative for Asthma (GINA). www.ginasthma.org/Guidelines/ guidelines-resources.html Date last updated: December 2010. Date last accessed: June 27, 2012.

2 Bel EH, Sousa A, Fleming L, et al. Unbiased Biomarkers for the Prediction of Respiratory Disease Outcome (U-BIOPRED) Consortium, Consensus Generation. Diagnosis and definition of severe refractory asthma: an international consensus statement from the Innovative Medicine Initiative (IMI). Thorax 2011; 66: 910-917.

3 Walsh LJ, Wong CA, Oborne J, et al. Adverse effects of oral corticosteroids in relation to dose in patients with lung disease. Thorax 2001; 56: 279-284.

4 Buhl R, Soler M, Matz J, et al. Omalizumab provides long-term control in patients with moderate-to-severe allergic asthma. Eur Respir J 2002; 20: 73-78.

5 Barnes PJ. New therapies for asthma: is there any progress? Trends Pharmacol Sci 2010; 31: 335-343.

6 Boner AL, Niero E, Antolini I, et al. Pulmonary function and bronchial hyperreactivity in asthmatic children with house dust mite allergy during prolonged stay in the Italian Alps (Misurina, 1756 m). Ann Allergy 1985; 54: 42-45.

7 Peroni DG, Boner AL, Vallone G, et al. Effective allergen avoidance at high altitude reduces allergen-induced bronchial hyperresponsiveness. Am J Respir Crit Care Med 1994; 149: 1442-1446.

8 Christie PE, Yntema JL, Tagari P, et al. Effect of altitude on urinary leukotriene (LT) E4 excretion and airway responsiveness to histamine in children with atopic asthma. Eur Respir J 1995; 8: 357-363.

9 Grootendorst DC, Dahlen SE, Van Den Bos JW, et al. Benefits of high altitude allergen avoidance in atopic adolescents with moderate to severe asthma, over and above treatment with high dose inhaled steroids. Clin Exp Allergy 2001; 31: 400-408.

10 Spieksma FT, Zuidema P, Leupen MJ. High altitude and housedust mites. Br Med J 1971; 1: 82-84.

11 Karagiannidis C, Hense G, Rueckert B, et al. High-altitude climate therapy reduces local airway inflammation and modulates lymphocyte activation. Scand J Immunol 2006; 63: 304-310.

12 Huss-Marp J, Kramer U, Eberlein B, et al. Reduced exhaled nitric oxide values in children with asthma after inpatient rehabilitation at high altitude. J Allergy Clin Immunol 2007; 120: 471-472.

13 Proceedings of the ATS workshop on refractory asthma. Current understanding, recommendations, and unanswered question. American Thoracic Society. Am J Respir Crit Care Med 2000; 162: 2341-2351. 
14 Juniper EF, O'Byrne PM, Guyatt GH, et al. Development and validation of a questionnaire to measure asthma control. Eur Respir J 1999; 14: 902-907.

15 Juniper EF, Buist AS, Cox FM, et al. Validation of a standardized version of the Asthma Quality of Life Questionnaire. Chest 1999; 115: 1265-1270.

16 Piccirillo JF, Merritt MG Jr, Richards ML. Psychometric and clinimetric validity of the 20-Item Sino-Nasal Outcome Test (SNOT-20). Otolaryngol Head Neck Surg 2002; 126: 41-47.

17 Quanjer PH, Tammeling GJ, Cotes JE, et al. Lung volumes and forced ventilatory flows. Report Working Party Standardization of Lung Function Tests, European Community for Steel and Coal. Official Statement of the European Respiratory Society. Eur Respir J 1993; 6: Suppl. 16, 5-40.

18 ATS statement. guidelines for six-minute walk test. Am J Respir Crit Care Med 2002; 166: 1317-117.

19 ATS/ERS recommendations for standardized procedures for the online and offline measurement of exhaled lower respiratory nitric oxide and nasal nitric oxide. Am J Respir Crit Care Med 2005; 171: 912-930.

20 Platts-Mills TA, Chapman MD. Dust mites: immunology, allergic disease, and environmental control. J Allergy Clin Immunol 1987; 80: 755-775.

21 Milanese M, Peroni D, Costella S, et al. Improved bronchodilator effect of deep inhalation after allergen avoidance in asthmatic children. J Allergy Clin Immunol 2004; 114: 505-511.

22 Rijssenbeek-Nouwens LH, Bel EH. High-altitude treatment: a therapeutic option for patients with severe, refractory asthma? Clin Exp Allergy 2011; 41: 775-782.
23 Pollen information. Allergiezentrum Schweiz. MeteoSchweiz Polleninfo. www.pollenundallergie.ch/polleninfo/pollenprognose. Date last updated: daily. Date last accessed: August 29, 2012.

24 Leuschner RM, Boehm W. Pollen and inorganic particles in the air of climatically very different places in Switzerland. Grana 1981; 20: 161-167.

25 Downs SH, Schindler C, Liu LJ, et al. Reduced exposure to PM10 and attenuated age-related decline in lung function. $N$ Engl J Med 2007; 357: 2338-2347.

26 European Environment Agency. Air Quality Maps of Europe. 2010. www.eea.europa.eu/themes/air/airbase/air-quality-mapsof-europe. Date last updated: April 13, 2011. Date last accessed August 29, 2012.

27 Manthous CA, Hall JB, Caputo MA, et al. Heliox improves pulsus paradoxus and peak expiratory flow in nonintubated patients with severe asthma. Am J Respir Crit Care Med 1995; 151: 310-314.

28 Haczku A, Panettieri RA Jr. Social stress and asthma: the role of corticosteroid insensitivity. J Allergy Clin Immunol 2010; 125: 550-558.

29 Chen E, Miller GE. Stress and inflammation in exacerbations of asthma. Brain Behav Immun 2007; 21: 993-999.

30 Sutherland ER, Goleva E, Jackson LP, et al. Vitamin D levels, lung function, and steroid response in adult asthma. Am J Respir Crit Care Med 2010; 181: 699-704.

31 Warner JO. Asthma, allergen avoidance and residence at high altitude. Pediatr Allergy Immunol 2009; 20: 509.

32 Reed CE. The natural history of asthma. J Allergy Clin Immunol 2006; 118: 543-548.

33 Cochrane LM, Clark CJ. Benefits and problems of a physical training program for asthmatic patients. Thorax 1990; 45: 345-351. 